ORIGINAL ARTICLE

\section{Bivalirudin for Patients with Acute Coronary Syndromes}

\author{
Gregg W. Stone, M.D., Brent T. McLaurin, M.D., David A. Cox, M.D., \\ Michel E. Bertrand, M.D., A. Michael Lincoff, M.D., Jeffrey W. Moses, M.D., \\ Harvey D. White, M.D., Stuart J. Pocock, Ph.D., James H. Ware, Ph.D., \\ Frederick Feit, M.D., Antonio Colombo, M.D., Philip E. Aylward, M.D., \\ Angel R. Cequier, M.D., Harald Darius, M.D., Walter Desmet, M.D., \\ Ramin Ebrahimi, M.D., Martial Hamon, M.D., Lars H. Rasmussen, M.D., \\ Hans-Jürgen Rupprecht, M.D., James Hoekstra, M.D., Roxana Mehran, M.D., \\ and E. Magnus Ohman, M.D., for the ACUITY Investigators*
}

\section{ABSTRACT}

\section{BACKGROUND}

Current guidelines for patients with moderate- or high-risk acute coronary syndromes recommend an early invasive approach with concomitant antithrombotic therapy, including aspirin, clopidogrel, unfractionated or low-molecular-weight heparin, and glycoprotein IIb/IIIa inhibitors. We evaluated the role of thrombin-specific anticoagulation with bivalirudin in such patients.

\section{METHODS}

We assigned 13,819 patients with acute coronary syndromes to one of three antithrombotic regimens: unfractionated heparin or enoxaparin plus a glycoprotein IIb/IIIa inhibitor, bivalirudin plus a glycoprotein IIb/IIIa inhibitor, or bivalirudin alone. The primary end points were a composite ischemia end point (death, myocardial infarction, or unplanned revascularization for ischemia), major bleeding, and the net clinical outcome, defined as the combination of composite ischemia or major bleeding.

\section{RESULTS}

Bivalirudin plus a glycoprotein IIb/IIIa inhibitor, as compared with heparin plus a glycoprotein IIb/IIIa inhibitor, was associated with noninferior 30-day rates of the composite ischemia end point (7.7\% and 7.3\%, respectively), major bleeding $(5.3 \%$ and $5.7 \%$ ), and the net clinical outcome end point (11.8\% and $11.7 \%$ ). Bivalirudin alone, as compared with heparin plus a glycoprotein IIb/IIIa inhibitor, was associated with a noninferior rate of the composite ischemia end point $(7.8 \%$ and $7.3 \%$, respectively; $\mathrm{P}=0.32$; relative risk, 1.08 ; $95 \%$ confidence interval $[\mathrm{CI}], 0.93$ to 1.24 ) and significantly reduced rates of major bleeding $(3.0 \%$ vs. $5.7 \%$; $\mathrm{P}<0.001$; relative risk, 0.53 ; $95 \% \mathrm{CI}, 0.43$ to 0.65$)$ and the net clinical outcome end point $(10.1 \%$ vs. $11.7 \%$; $\mathrm{P}=0.02$; relative risk, 0.86 ; $95 \% \mathrm{CI}, 0.77$ to 0.97 ).

\section{CONCLUSIONS}

In patients with moderate- or high-risk acute coronary syndromes who were undergoing invasive treatment with glycoprotein IIb/IIIa inhibitors, bivalirudin was associated with rates of ischemia and bleeding that were similar to those with heparin. Bivalirudin alone was associated with similar rates of ischemia and significantly lower rates of bleeding. (ClinicalTrials.gov number, NCT00093158.)
From Columbia University Medical Center and the Cardiovascular Research Foundation, New York (G.W.S., J.W.M., R.M.); AnMed Health, Anderson, SC (B.T.M.); Mid Carolina Cardiology, Charlotte, NC (D.A.C.); Hôpital Cardiologique, Lille, France (M.E.B.); Cleveland Clinic, Cleveland (A.M.L.); Auckland City Hospital, Auckland, New Zealand (H.D.W.); London School of Hygiene and Tropical Medicine, London (S.J.P.); Harvard University, Boston (J.H.W.); New York University School of Medicine, New York (F.F.); Ospedale San Raphael, Milan (A.C.); Flinders Medical Center, Adelaide, Australia (P.E.A.); Hospital Universitari de Bellvitge, Barcelona (A.R.C.); Krankenhaus Neukölln, Berlin (H.D.); University Hospital, Gasthuisberg, Leuven, Belgium (W.D.); UCLA and the Greater Los Angeles Veterans Affairs Medical Center, Los Angeles (R.E.); University Hospital, Normandy, France (M.H.); Aarhus University Hospital, Aalborg Hospital, Aalborg, Denmark (L.H.R.); GPR Klinikum Rüsselsheim, Rüsselsheim, Germany (H.-J.R.); Wake Forest University, WinstonSalem, NC (J.H.); and Duke University Medical Center, Durham, NC (E.M.O.). Address reprint requests to $\mathrm{Dr}$. Stone at Columbia University Medical Center, Cardiovascular Research Foundation, 111 E. 59th St., 11th Fl., New York, NY 10022, or at gs2184@columbia.edu.

*The names of the participants in the Acute Catheterization and Urgent Intervention Triage Strategy (ACUITY) trial appear in the Supplementary Appendix (available with the full text of this article at www.nejm.org).

N Engl J Med 2006;355:2203-16. Copyright @ 2006 Massachusetts Medical Society. 
M

ORE THAN 1.4 MILLION PERSONS ARE admitted to hospitals in the United States every year with acute coronary syndromes (e.g., unstable angina or myocardial infarction without ST-segment elevation). ${ }^{1}$ An early invasive strategy for patients with moderate- or high-risk acute coronary syndromes, consisting of angiography followed by percutaneous coronary intervention (PCI), coronary-artery bypass grafting (CABG), or medical management, results in higher rates of event-free survival than does conservative care $^{2}$ and is recommended by the American Heart Association, the American College of Cardiology, and the European Society of Cardiology. ${ }^{3-5}$ Aspirin, clopidogrel, a platelet glycoprotein IIb/ IIIa inhibitor, and an antithrombotic agent (either unfractionated or low-molecular-weight heparin) are also recommended for patients for whom an invasive strategy is chosen. ${ }^{3-5}$ Nonetheless, the rates of death and myocardial infarction remain considerable, and this intensive adjunctive pharmacologic regimen results in frequent hemorrhagic complications that have been independently associated with early and late mortality rates. ${ }^{6-8}$

Bivalirudin (Angiomax, the Medicines Company) is a direct-acting synthetic antithrombotic agent that has been approved as an alternative to unfractionated heparin for patients with acute coronary syndromes who are undergoing PCI. In the Randomized Evaluation in PCI Linking Angiomax to Reduced Clinical Events 2 (REPLACE-2) trial, bivalirudin monotherapy, as compared with unfractionated heparin plus glycoprotein IIb/IIIa inhibitors, resulted in a significant reduction in rates of major and minor bleeding (as defined in the trial), with similar rates of ischemic events and death among patients with stable or unstable angina who were undergoing PCI.9,10 We examined the usefulness of bivalirudin as part of an early invasive strategy with optimal antiplatelet therapy in patients with acute coronary syndromes.

\section{METHODS}

\section{STUDY DESIGN}

The Acute Catheterization and Urgent Intervention Triage Strategy (ACUITY) trial was a prospective, open-label, randomized, multicenter trial in which we compared heparin plus a glycoprotein IIb/IIIa inhibitor, bivalirudin plus a glycoprotein IIb/IIIa inhibitor, and bivalirudin alone in patients with moderate- or high-risk acute coronary syndromes who were undergoing an early invasive strategy. The study protocol has been described previously in detail. ${ }^{11}$ The trial was sponsored by the Medicines Company and Nycomed.

The study was designed by Drs. Stone, Bertrand, Lincoff, Moses, Ohman, White, Pocock, and Ware in collaboration with the sponsors. The execution of the study was supervised by the sponsors in collaboration with the executive and steering committees (see the Supplementary Appendix, available with the full text of this article at www. nejm.org). Dr. Stone had full access to the entire study database and prepared the manuscript. Data analysis was performed by the study sponsors but was independently confirmed by the Cardiovascular Research Foundation, an affiliate of Columbia University Medical Center. Dr. Stone vouches for the accuracy and completeness of the data.

\section{PATIENTS}

Patients 18 years of age or older with symptoms of unstable angina lasting at least 10 minutes within the preceding 24 hours were eligible for enrollment if one or more of the following criteria were met: new ST-segment depression or transient elevation of at least $1 \mathrm{~mm}$; elevations in the troponin I, troponin T, or creatine kinase MB levels; known coronary artery disease; or all four other variables for predicting Thrombolysis in Myocardial Infarction (TIMI) risk scores for unstable angina. ${ }^{12}$ Exclusion criteria were myocardial infarction associated with acute ST-segment elevation or shock; bleeding diathesis or major bleeding episode within 2 weeks before the episode of angina; thrombocytopenia; a calculated creatinine clearance rate of less than $30 \mathrm{ml}$ per minute; recent administration of abciximab, warfarin, fondaparinux, fibrinolytic agents, bivalirudin, or two or more doses of low-molecular-weight heparin; and allergy to any of the study drugs or to iodinated contrast medium that could not be controlled in advance with medication. The study was approved by the institutional review board or ethics committee at each participating center, and all patients provided written, informed consent.

\section{RANDOMIZATION AND STUDY PROTOCOL}

Telephone randomization was performed in blocks of six, stratified according to the site and the use of or intent to administer a thienopyridine before angiography. Patients were assigned equally in open-label fashion to one of the following three 
antithrombotic regimens that were started immediately after randomization: heparin plus a glycoprotein IIb/IIIa inhibitor (the control group), bivalirudin plus a glycoprotein IIb/IIIa inhibitor, or bivalirudin alone (Fig. 1). Either unfractionated heparin or enoxaparin was allowed in the control group. However, each site was required to prespecify one agent and then use it exclusively, unless one of the types of heparin had been administered before randomization, in which case that same agent was continued in order to minimize crossovers. ${ }^{13}$

Detailed antithrombotic dosing recommendations for the trial have been described previously. ${ }^{11}$ Unfractionated heparin was administered as an intravenous bolus of $60 \mathrm{IU}$ per kilogram of body weight plus an infusion of $12 \mathrm{IU}$ per kilogram per hour to achieve an activated partial-thromboplastin time of 50 to 75 seconds before angiography and an activated clotting time of 200 to $250 \mathrm{sec}$ onds during PCI. One milligram of enoxaparin per kilogram was administered subcutaneously twice a day before angiography. An intravenous bolus of an additional $0.3 \mathrm{mg}$ per kilogram was administered before PCI if the most recent subcutaneous dose had been given more than 8 hours earlier, or an intravenous bolus of an additional $0.75 \mathrm{mg}$ per kilogram was administered before PCI if the most recent subcutaneous dose had been given more than 16 hours earlier. Bivalirudin was begun before angiography, with an intravenous bolus of $0.1 \mathrm{mg}$ per kilogram and an infusion of $0.25 \mathrm{mg}$ per kilogram per hour. ${ }^{14,15}$ Before PCI, an additional intravenous bolus of $0.5 \mathrm{mg}$ per kilogram was administered, and the infusion was increased to 1.75 mg per kilogram per hour. ${ }^{9}$ All antithrombotic agents were discontinued according to the protocol at the completion of angiography or PCI but could be continued at low doses at the discretion of the operator. Antithrombotic monitoring was not performed in patients who were treated with enoxaparin or bivalirudin.

Patients assigned to heparin plus glycoprotein

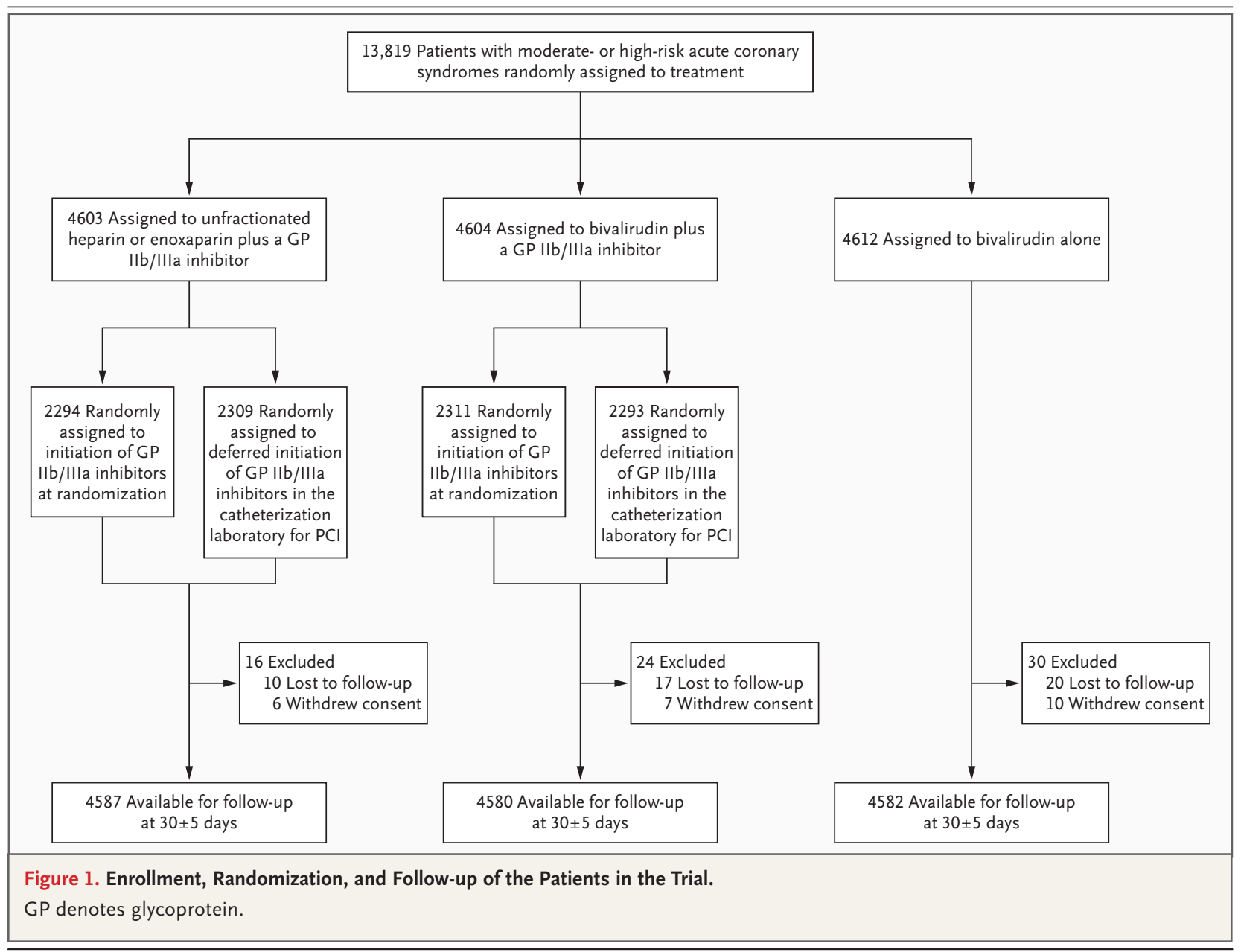


IIb/IIIa inhibitors or bivalirudin plus glycoprotein IIb/IIIa inhibitors were randomly assigned again in a two-by-two factorial design to treatment with glycoprotein IIb/IIIa inhibitors, in all patients immediately after randomization (the "upstream" group), or to deferred treatment with glycoprotein IIb/IIIa inhibitors, for use only in patients undergoing PCI starting in the cardiac catheterization laboratory (Fig. 1). ${ }^{16-19}$ The results of this subrandomization are not reported here; the results are reported with the upstream and deferred subgroups pooled. The use of glycoprotein IIb/IIIa inhibitors was permitted before angiography in patients with severe breakthrough ischemia who were randomly assigned to deferred glycoprotein IIb/IIIa inhibitor use or bivalirudin monotherapy and was also permitted during PCI in patients receiving bivalirudin monotherapy who had procedural complications. ${ }^{11}$

Angiography was performed in all patients within 72 hours after randomization. Patients were then triaged to PCI, CABG, or medical management at the discretion of the physician. Aspirin, 300 to $325 \mathrm{mg}$ orally or 250 to $500 \mathrm{mg}$ intravenously, was administered daily during the initial hospitalization, followed by 75 to $325 \mathrm{mg}$ daily indefinitely after discharge. The initial dose and timing of clopidogrel were left to the discretion of the investigator according to local standards, although a loading dose of $300 \mathrm{mg}$ or more was recommended in all patients no later than 2 hours after PCI. A daily dose of $75 \mathrm{mg}$ of clopidogrel was recommended for 1 year in all patients with coronary artery disease.

\section{END POINTS}

The following three primary 30-day end points, measured as cumulative events occurring within 25 to 35 days after randomization, were prespecified: a composite ischemia end point (death from any cause, myocardial infarction, or unplanned revascularization for ischemia), major bleeding (not related to $\mathrm{CABG}$ ), and a net clinical outcome end point (defined as the occurrence of the composite ischemia end point or major bleeding). Definitions of the primary end points have been previously detailed. ${ }^{11}$ Major bleeding was defined as the cumulative occurrence within 25 to 35 days after randomization of intracranial or intraocular bleeding, hemorrhage at the access site requiring intervention, hematoma with a diameter of at least $5 \mathrm{~cm}$, a reduction in hemoglobin levels of at least $4 \mathrm{~g}$ per deciliter without an overt bleeding source or at least $3 \mathrm{~g}$ per deciliter with such a source, reoperation for bleeding, or transfusion of a blood product. A clinical events committee that was unaware of the treatment assignments adjudicated all primary end-point events with the use of original source documents.

\section{STATISTICAL ANALYSIS}

The trial was powered for separate comparisons between the control group and each of the two investigational groups. We used sequential noninferiority and superiority analyses with hierarchical end-point testing, with the type I error controlled by the Benjamini and Hochberg procedure, ${ }^{20}$ as previously described..$^{11}$ Noninferiority was declared if the upper limit of the one-sided $97.5 \%$ confidence interval (CI) for the event rate in the investigational group did not exceed a relative margin of $25 \%$ from the event rate in the control group, equivalent to a one-sided test with an alpha value of 0.025 . A two-sided alpha value of 0.05 was used for superiority testing.

The anticipated 30-day event rates for the composite ischemia end point, major bleeding, and the net clinical outcome end point were $6.5 \%$, $9.0 \%$, and $12.4 \%$, respectively, in the control group; $5.3 \%, 7.5 \%$, and $10.3 \%$, respectively, in the group receiving bivalirudin plus glycoprotein IIb/IIIa inhibitors; and $6.5 \%, 6.0 \%$, and $10.5 \%$, respectively, in the group receiving bivalirudin alone. ${ }^{11}$ For the comparison of bivalirudin plus glycoprotein IIb/IIIa inhibitors with heparin plus glycoprotein IIb/IIIa inhibitors, with 4600 patients in each group, the trial had more than $99 \%$ statistical power to demonstrate noninferiority for the three primary end points and $88 \%$ power to demonstrate superiority for the net clinical outcome end point. For the comparison of bivalirudin alone with heparin plus glycoprotein IIb/IIIa inhibitors, the trial had $87 \%$ power to demonstrate noninferiority for the composite ischemia end point, 99\% power to demonstrate both noninferiority and superiority for major bleeding, and $99 \%$ and $81 \%$ power to demonstrate noninferiority and superiority, respectively, for the net clinical outcome end point.

Categorical variables were compared with the chi-square test or Fisher's exact test. Continuous variables were compared with the nonparametric Wilcoxon rank-sum test. Time-to-event distributions were displayed according to the Kaplan-Meier method and were compared with the use of the 
log-rank test. All outcomes were evaluated by intention-to-treat analyses.

\section{RESULTS}

\section{PATIENTS}

Between August 23, 2003, and December 5, 2005, we enrolled 13,819 patients with acute coronary syndromes at 450 centers in 17 countries. Baseline characteristics were well balanced among the study groups (Table 1). The median age of the patients was 63 years, and 70\% were men. Myocardial infarction without ST-segment elevation (elevated baseline creatine kinase MB or troponin levels) was present in $59 \%$ of patients, whereas $41 \%$ had unstable angina.

Angiography was performed during the initial hospitalization in $99 \%$ of patients at a median of 19.6 hours after admission, after which $56 \%$ of the patients underwent PCI, 11\% underwent CABG, and 33\% received medical therapy (Table 2). Stents were used in $93 \%$ of patients undergoing PCI, $65 \%$

\begin{tabular}{|c|c|c|c|}
\hline Characteristic & $\begin{array}{l}\text { Unfractionated } \\
\text { Heparin or Enoxaparin } \\
\text { plus Glycoprotein } \\
\text { Ilb/IIIa Inhibitors } \\
\text { (N=4603) }\end{array}$ & $\begin{array}{c}\text { Bivalirudin plus } \\
\text { Glycoprotein IIb/IIla } \\
\text { Inhibitors } \\
(\mathrm{N}=4604)\end{array}$ & $\begin{array}{l}\text { Bivalirudin Alone } \\
\quad(\mathrm{N}=4612)\end{array}$ \\
\hline \multicolumn{4}{|l|}{ Age $-y r$} \\
\hline Median & 63 & 63 & 63 \\
\hline Range & $23-91$ & $21-95$ & $20-92$ \\
\hline \multicolumn{4}{|l|}{ Weight — kg } \\
\hline Median & 83 & 83 & 84 \\
\hline Interquartile range & $73-95$ & $73-95$ & $73-96$ \\
\hline Male sex — no. (\%) & $3249(70.6)$ & $3218(69.9)$ & $3195(69.3)$ \\
\hline \multicolumn{4}{|l|}{ Medical history — no./total no. (\%) } \\
\hline Diabetes & $1298 / 4564(28.4)$ & $1267 / 4568(27.7)$ & $1287 / 4577(28.1)$ \\
\hline Insulin-requiring diabetes & $389 / 4564(8.5)$ & $396 / 4568(8.7)$ & $408 / 4577(8.9)$ \\
\hline Hypertension & $3058 / 4577(66.8)$ & $3074 / 4577(67.2)$ & $3080 / 4593(67.1)$ \\
\hline Hyperlipidemia & $2580 / 4511(57.2)$ & $2588 / 4508(57.4)$ & $2579 / 4521(57.0)$ \\
\hline Current smoker & $1308 / 4508(29.0)$ & $1323 / 4522(29.3)$ & $1312 / 4527(29.0)$ \\
\hline Myocardial infarction & $1419 / 4493(31.6)$ & $1372 / 4491(30.5)$ & $1431 / 4499(31.8)$ \\
\hline Percutaneous coronary intervention & $1780 / 4567(39.0)$ & $1720 / 4554(37.8)$ & $1820 / 4562(39.9)$ \\
\hline Coronary-artery bypass grafting & $834 / 4588(18.2)$ & $801 / 4592(17.4)$ & $830 / 4594(18.1)$ \\
\hline Renal insufficiency* & $826 / 4298(19.2)$ & $824 / 4303(19.1)$ & $818 / 4339(18.9)$ \\
\hline $\begin{array}{l}\text { Elevation of cardiac biomarker levels - } \\
\text { no./total no. (\%) }\end{array}$ & $2503 / 4213(59.4)$ & $2479 / 4238(58.5)$ & $2570 / 4263(60.3)$ \\
\hline Elevation of troponin levels - no./total no. (\%) & $2290 / 3931(58.3)$ & $2276 / 3982(57.2)$ & $2349 / 3971(59.2)$ \\
\hline ST-segment deviation $\geq 1 \mathrm{~mm}-$ no./total no. (\%) & $1618 / 4598(35.2)$ & $1628 / 4599(35.4)$ & $1579 / 4607(34.3)$ \\
\hline $\begin{array}{l}\text { Elevation of cardiac biomarker levels or ST-seg- } \\
\text { ment deviation } \geq 1 \mathrm{~mm}-\text { no./total no. (\%) }\end{array}$ & $3171 / 4340(73.1)$ & $3119 / 4362(71.5)$ & $3173 / 4385(72.4)$ \\
\hline \multicolumn{4}{|l|}{ TIMI risk score - no./total no. (\%) † } \\
\hline $0-2$ & $654 / 4070(16.1)$ & $630 / 4090(15.4)$ & $637 / 4077(15.6)$ \\
\hline $3-4$ & $2184 / 4070(53.7)$ & $2269 / 4090(55.5)$ & $2223 / 4077(54.5)$ \\
\hline $5-7$ & $1232 / 4070(30.3)$ & $1191 / 4090(29.1)$ & $1217 / 4077$ (29.9) \\
\hline
\end{tabular}

* Renal insufficiency was defined as a calculated creatinine clearance rate of less than $60 \mathrm{ml}$ per minute as determined by the Cockcroft-Gault equation.

$\dagger$ Thrombolysis in Myocardial Infarction (TIMI) risk scores assess the prognosis for patients with acute coronary syndromes; higher scores indicate greater risk. ${ }^{12}$ 


\begin{tabular}{|c|c|c|c|}
\hline Variable & $\begin{array}{l}\text { Unfractionated } \\
\text { Heparin or } \\
\text { Enoxaparin plus } \\
\text { Glycoprotein IIb/IIla } \\
\text { Inhibitors } \\
(\mathrm{N}=4603)\end{array}$ & $\begin{array}{l}\text { Bivalirudin plus } \\
\text { Glycoprotein IIb/IIIa } \\
\text { Inhibitors } \\
(\mathrm{N}=4604)\end{array}$ & $\begin{array}{l}\text { Bivalirudin Alone } \\
(\mathrm{N}=4612)\end{array}$ \\
\hline Angiography performed — no. (\%) & $4565(99.2)$ & $4547(98.8)$ & $4561(98.9)$ \\
\hline Hours from admission to angiography — median (interquartile range)* & $19.7(7.0-29.3)$ & $19.5(7.0-28.2)$ & $19.8(7.3-29.0)$ \\
\hline Hours from admission to randomization — median (interquartile range) & $6.1(2.0-15.5)$ & $6.0(2.0-15.4)$ & $6.0(2.0-15.1)$ \\
\hline $\begin{array}{l}\text { Hours from randomization to initiation of antithrombotic study drug } \\
\quad-\text { median (interquartile range) } \dagger\end{array}$ & $0.4(0.1-0.9)$ & $0.7(0.4-1.1)$ & $0.6(0.3-1.0)$ \\
\hline $\begin{array}{l}\text { Hours from antithrombotic study drug to angiography - median } \\
\text { (interquartile range) } \dagger\end{array}$ & $4.0(1.2-18.1)$ & $3.5(0.9-18.2)$ & $3.9(1.0-19.0)$ \\
\hline $\begin{array}{l}\text { Hours from antithrombotic study drug to } \mathrm{PCl} \text { — median (interquartile } \\
\text { range) } \dagger\end{array}$ & $4.1(1.5-19.0)$ & $3.9(1.3-19.0)$ & $4.1(1.4-20.0)$ \\
\hline \multicolumn{4}{|l|}{ Treatment strategy — no. (\%) } \\
\hline $\mathrm{PCl}$ & $2561(55.6)$ & $2609(56.7)$ & $2619(56.8)$ \\
\hline Coronary-artery bypass grafting & 549 (11.9) & $499(10.8)$ & $491(10.6)$ \\
\hline Medical management & $1493(32.4)$ & $1496(32.5)$ & $1502(32.6)$ \\
\hline \multicolumn{4}{|l|}{ Antithrombotic medications - no. (\%) } \\
\hline Before randomization & $3010(65.4)$ & $2907(63.1)$ & $2945(63.9)$ \\
\hline Unfractionated heparin & $1910(41.5)$ & $1858(40.4)$ & $1870(40.5)$ \\
\hline Low-molecular-weight heparin & $1209(26.3)$ & $1144(24.8)$ & $1172(25.4)$ \\
\hline \multicolumn{4}{|l|}{ After randomization and before angiography } \\
\hline Unfractionated heparin & 2206 (47.9) & $82(1.8)$ & $66(1.4)$ \\
\hline Enoxaparin & $2182(47.4)$ & $17(0.4)$ & $20(0.4)$ \\
\hline Bivalirudin & $6(0.1)$ & $4420(96.0)$ & $4471(96.9)$ \\
\hline \multicolumn{4}{|l|}{ Antiplatelet medications } \\
\hline Aspirin before angiography or $\mathrm{PCl}$ - no./total no. (\%) & $4446 / 4535(98.0)$ & $4427 / 4528(97.8)$ & $4441 / 4535(97.9)$ \\
\hline Thienopyridine before angiography or $\mathrm{PCl}-$ no./total no. (\%) & $2842 / 4526(62.8)$ & $2924 / 4520(64.7)$ & $2911 / 4531(64.2)$ \\
\hline Clopidogrel & $2819 / 4527(62.3)$ & $2904 / 4520(64.2)$ & 2897/4531 (63.9) \\
\hline Ticlopidine & $42 / 4534(0.9)$ & $36 / 4524(0.8)$ & $31 / 4531(0.7)$ \\
\hline
\end{tabular}

of whom received drug-eluting stents. In the control group, after randomization, unfractionated heparin and enoxaparin were selected with similar frequencies. The median maximum activated clotting time among patients undergoing PCI with unfractionated heparin was 239 seconds (interquartile range, 211 to 291).

Glycoprotein IIb/IIIa inhibitors were used during PCI in $9.1 \%$ of patients treated with bivalirudin alone (for procedural complications in $6.5 \%$ ). The most common procedural complications leading to the use of glycoprotein IIb/IIIa inhibitors were the presence of new or suspected thrombus, slow flow (TIMI flow grade 2), or no reflow (TIMI flow grade 0 or 1 ).

\section{IN-HOSPITAL ADVERSE EVENTS}

On the basis of on-site reporting without central adjudication, the most frequent nonprocedural adverse events during the initial hospitalization were chest pain (3.6\% of patients), headache (3.1\%), back pain $(2.8 \%)$, and nausea $(2.3 \%)$, which occurred with similar frequency in the three trial groups. Procedural complications were reported more frequently in the group assigned to bivalirudin alone than in the other two groups, a finding that was consistent with the protocol-specified requirement to provide an indication for provisional use of glycoprotein IIb/IIIa inhibitors. Blinded angiographic analyses performed at a core laboratory showed no significant differences in the incidence, nature, or 


\begin{tabular}{|c|c|c|c|}
\hline \multicolumn{4}{|l|}{ Table 2. (Continued.) } \\
\hline Variable & $\begin{array}{l}\text { Unfractionated } \\
\text { Heparin or } \\
\text { Enoxaparin plus } \\
\text { Glycoprotein IIb/IIla } \\
\text { Inhibitors } \\
(\mathrm{N}=4603)\end{array}$ & $\begin{array}{l}\text { Bivalirudin plus } \\
\text { Glycoprotein IIb/IIla } \\
\text { Inhibitors } \\
\text { (N=4604) }\end{array}$ & $\begin{array}{l}\text { Bivalirudin Alone } \\
(\mathrm{N}=4612)\end{array}$ \\
\hline Glycoprotein IIb/IIla inhibitor before randomization - no. (\%) & $374(8.1)$ & $350(7.6)$ & $307(6.7)$ \\
\hline Eptifibatide & $222(4.8)$ & $213(4.6)$ & $193(4.2)$ \\
\hline Tirofiban & $154(3.3)$ & $136(3.0)$ & $114(2.5)$ \\
\hline Abciximab & $13(0.3)$ & $10(0.2)$ & $9(0.2)$ \\
\hline $\begin{array}{l}\text { Glycoprotein IIb/IIla inhibitor after randomization and before angio- } \\
\text { graphy }- \text { no. (\%) }\end{array}$ & $2305(50.1)$ & $2248(48.8)$ & $31(0.7)$ \\
\hline Eptifibatide & $1486(32.3)$ & $1448(31.5)$ & $19(0.4)$ \\
\hline Tirofiban & $802(17.4)$ & $784(17.0)$ & $11(0.2)$ \\
\hline Abciximab & $17(0.4)$ & $16(0.3)$ & $1(<0.1)$ \\
\hline Glycoprotein IIb/IIla inhibitor during PCI — no./total no. (\%) & $2473 / 2561(96.6)$ & $2523 / 2609$ (96.7) & $238 / 2619(9.1)$ \\
\hline Eptifibatide & $1526 / 2561(59.6)$ & $1588 / 2609$ (60.9) & $119 / 2619(4.5)$ \\
\hline Tirofiban & $492 / 2561$ (19.2) & $513 / 2609$ (19.7) & $20 / 2619(0.8)$ \\
\hline Abciximab & $455 / 2561(17.8)$ & $425 / 2609(16.3)$ & $99 / 2619$ (3.8) \\
\hline \multicolumn{4}{|l|}{$\begin{array}{l}\text { Medications taken regularly after hospital discharge through } 30 \text { days - } \\
\text { no./total no. (\%) }\end{array}$} \\
\hline Aspirin & $4088 / 4411$ (92.7) & $4076 / 4388$ (92.9) & $4094 / 4394(93.2)$ \\
\hline Thienopyridine & $2940 / 4411(66.7)$ & $3012 / 4388(68.6)$ & $3013 / 4394(68.6)$ \\
\hline Beta-blocker & $3363 / 4411(76.2)$ & $3387 / 4388(77.2)$ & $3361 / 4394$ (76.5) \\
\hline $\begin{array}{l}\text { Angiotensin converting-enzyme inhibitor or angiotensin-receptor } \\
\text { blocker }\end{array}$ & $2589 / 4411(58.7)$ & $2619 / 4388(59.7)$ & $2642 / 4394(60.1)$ \\
\hline Statin & $3530 / 4411(80.0)$ & $3510 / 4388(80.0)$ & $3549 / 4394(80.8)$ \\
\hline
\end{tabular}

angiographic outcome of procedural complications among the three groups.

\section{CLINICAL OUTCOMES}

Bivalirudin plus glycoprotein IIb/IIIa inhibitors, as compared with heparin plus glycoprotein IIb/IIIa inhibitors, resulted in noninferior 30-day rates of the composite ischemia end point $(7.7 \%$ and $7.3 \%$, respectively; $\mathrm{P}=0.39$; relative risk, 1.07 ; $95 \% \mathrm{CI}$, 0.92 to 1.23 ), major bleeding (5.3\% and $5.7 \%$; $\mathrm{P}=0.38$; relative risk, 0.93 ; $95 \% \mathrm{CI}, 0.78$ to 1.10 ), and the net clinical outcome end point $(11.8 \%$ and $11.7 \%$; $\mathrm{P}=0.93$; relative risk, $1.01 ; 95 \% \mathrm{CI}, 0.90$ to 1.12). Bivalirudin alone, as compared with heparin plus glycoprotein IIb/IIIa inhibitors, resulted in a noninferior rate of the composite ischemia end point $(7.8 \%$ and $7.3 \%$, respectively; $\mathrm{P}=0.32$; relative risk, 1.08; $95 \%$ CI, 0.93 to 1.24 ), a significantly reduced rate of major bleeding $(3.0 \%$ and $5.7 \%$; $\mathrm{P}<0.001$; relative risk, 0.53 ; $95 \% \mathrm{CI}, 0.43$ to 0.65 ), and a reduced rate of the net clinical outcome end point $(10.1 \%$ and $11.7 \% ; \mathrm{P}=0.02$; relative risk, 0.86 ; $95 \%$ CI, 0.77 to 0.97 ) (Table 3 and Fig. 2). Bivalirudin monotherapy also decreased the rates of bleeding from any cause (including bleeding related to CABG), minor bleeding, major and minor bleeding according to the TIMI scale, and blood transfusion (Table 3).

The treatment effects of bivalirudin monotherapy were consistent among multiple prespecified subgroups, including patients who had positive tests for biomarkers, those undergoing PCI, those who were randomly assigned to immediate or deferred treatment with glycoprotein IIb/IIIa in- 


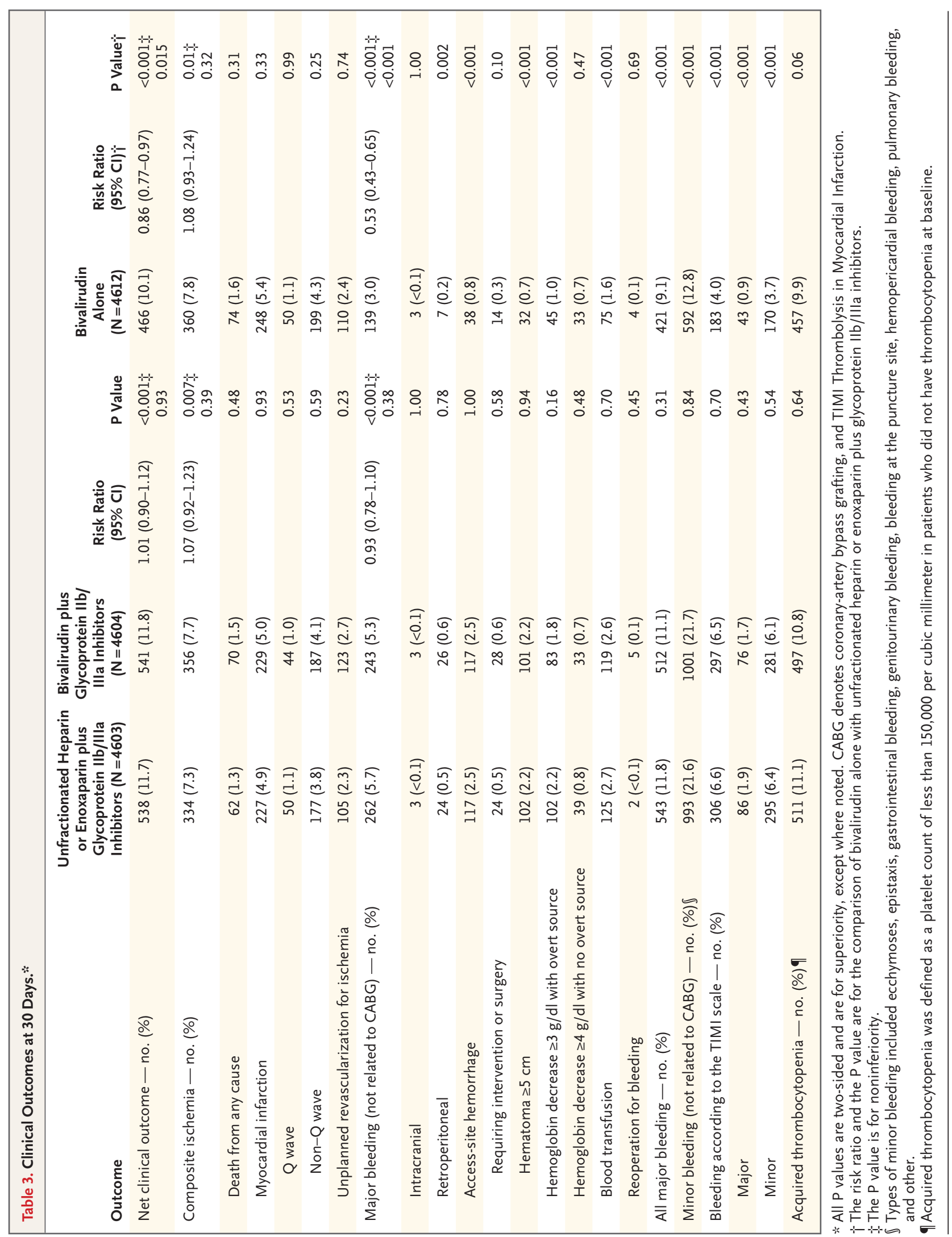




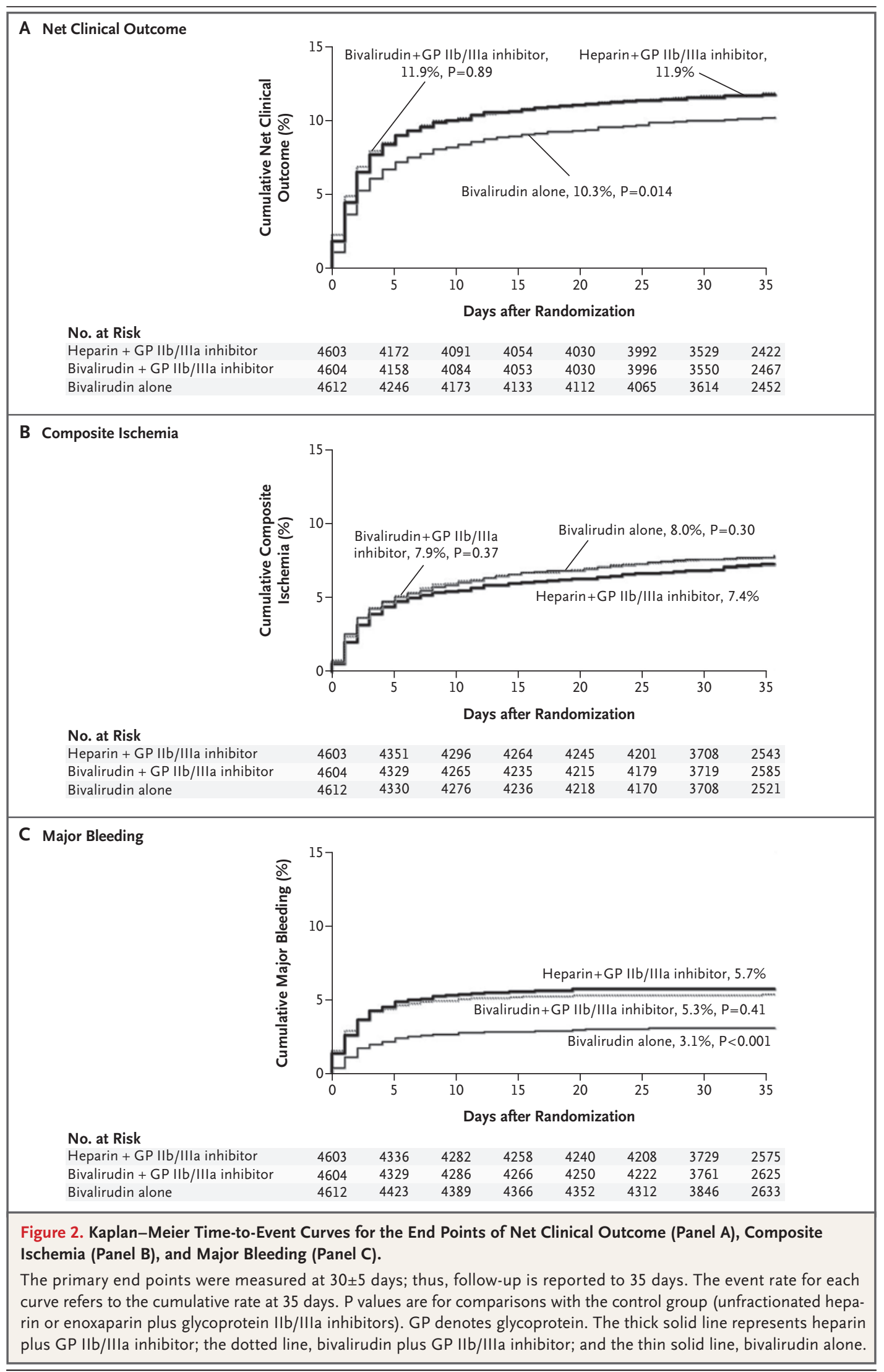

N ENGLJ MED 355;21 WWW.NEJM.ORG NOVEMBER 23, 2006 


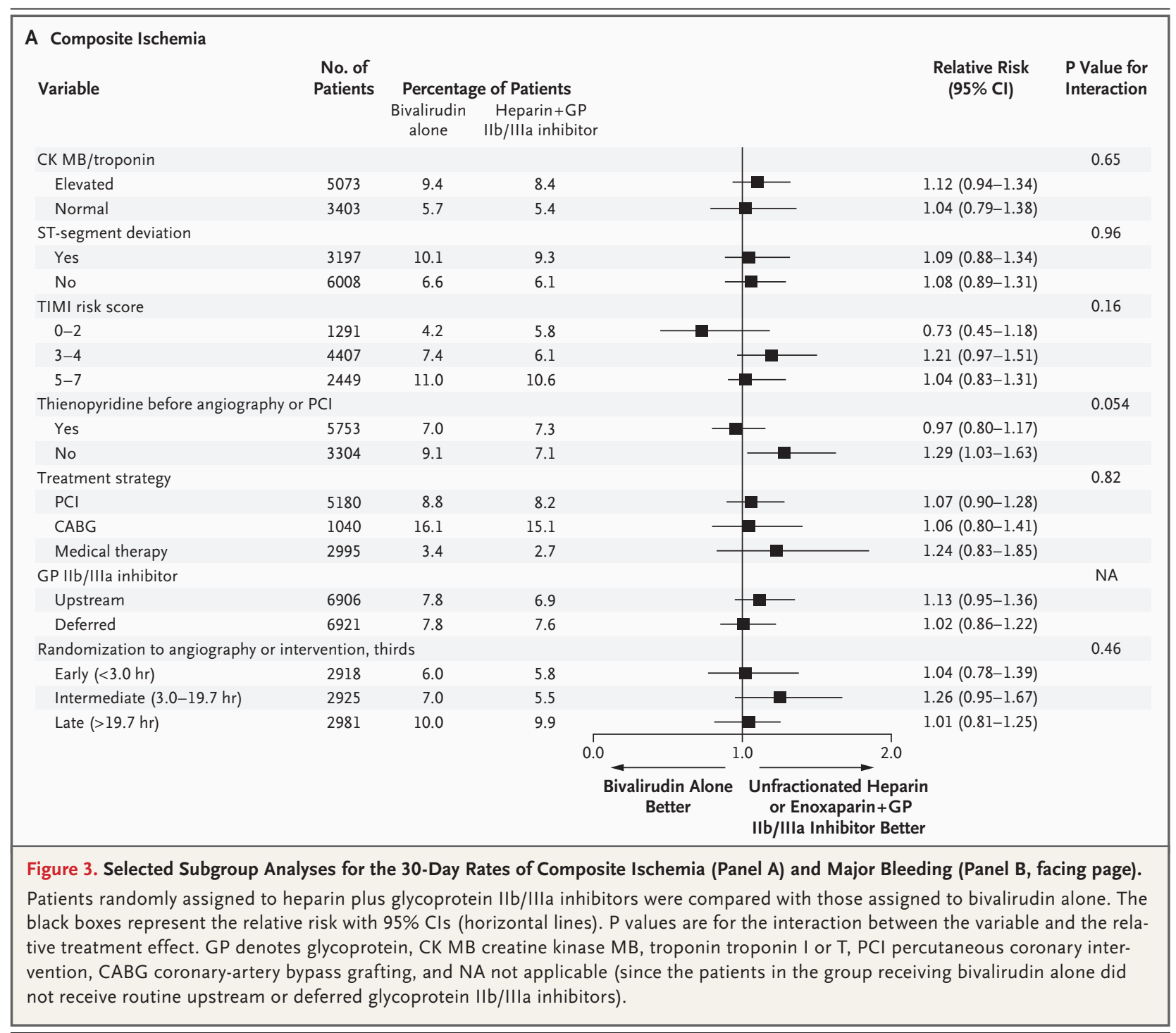

hibitors, and those who did not undergo early angiography (Fig. 3; see also the figure in the Supplementary Appendix). Among the 2472 patients who underwent angiography or intervention more than 24 hours after randomization (median, 45.0 hours; interquartile range, 28.4 to 69.2), bivalirudin monotherapy, as compared with heparin plus glycoprotein IIb/IIIa inhibitors, resulted in a similar rate of the composite ischemia end point $(8.9 \%$ and $9.1 \%, P=0.89$ ), a reduced rate of major bleeding $(3.3 \%$ and $8.9 \%, \mathrm{P}<0.001)$, and a reduced rate of the net clinical outcome end point $(11.4 \%$ and $16.4 \%, \mathrm{P}=0.003)$.

An interaction effect with borderline significance $(\mathrm{P}=0.054)$ was noted in only one subgroup analysis. Among patients receiving a thienopyri- dine before angiography or PCI, ischemic events occurred with similar frequency in the bivalirudin monotherapy group and in the group assigned to heparin plus a glycoprotein IIb/IIIa inhibitor $(7.0 \%$ and $7.3 \%$, respectively; relative risk, $0.97 ; 95 \% \mathrm{CI}$, 0.80 to 1.17). In contrast, among patients who did not receive a thienopyridine before angiography or PCI, ischemic events were more frequent with bivalirudin monotherapy than with heparin plus a glycoprotein IIb/IIIa inhibitor $(9.1 \%$ and $7.1 \%$; relative risk, 1.29; 95\% CI, 1.03 to 1.63). Bivalirudin monotherapy, as compared with heparin plus a glycoprotein IIb/IIIa inhibitor, reduced major bleeding regardless of whether patients were pretreated with a thienopyridine (Fig. 3).

Patients in the control group who received 


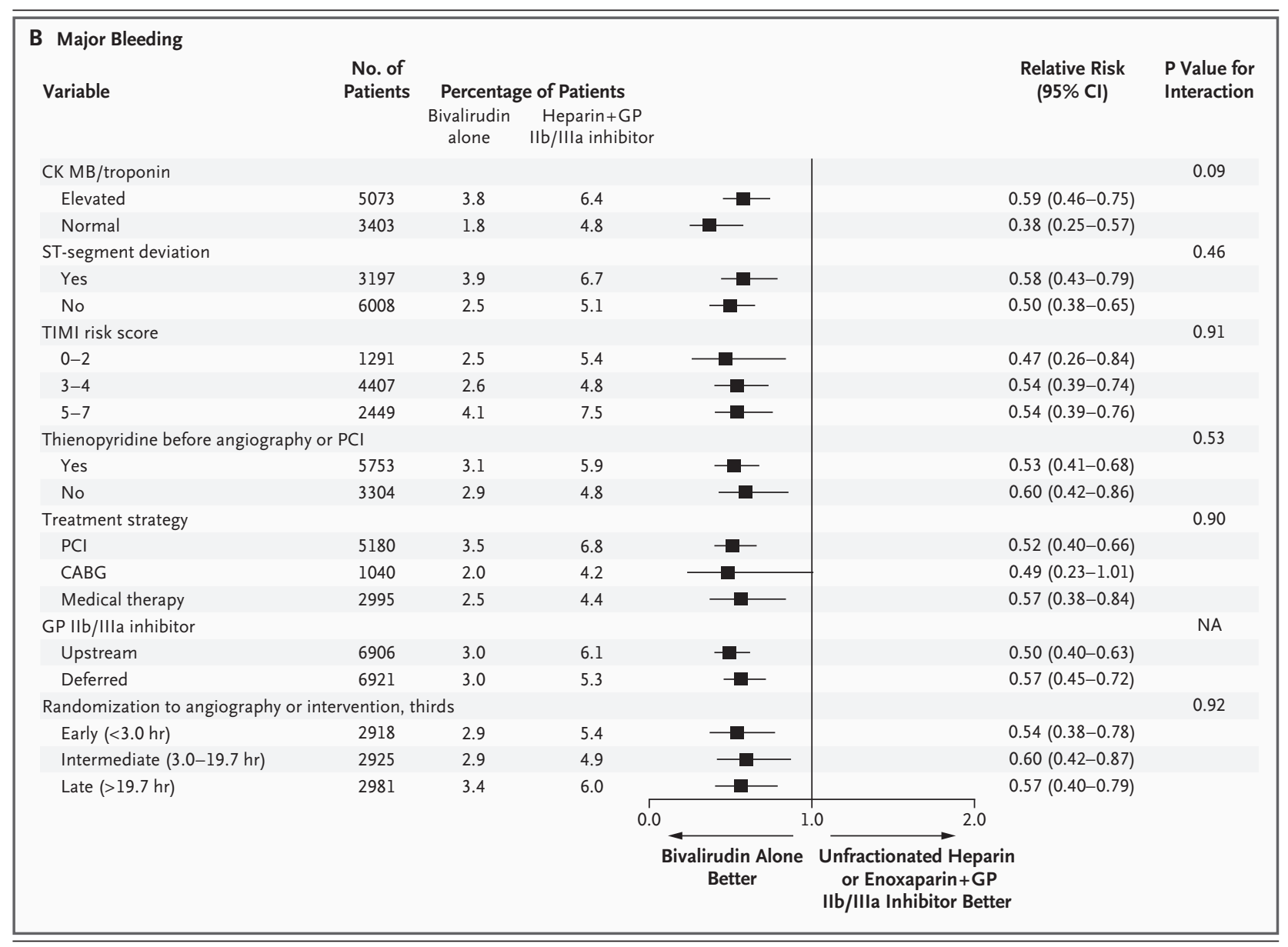

unfractionated heparin and those who received enoxaparin had similar 30-day rates of the composite ischemia end point $(6.8 \%$ and $7.7 \%$, respectively; $\mathrm{P}=0.29)$, major bleeding $(5.9 \%$ and $5.5 \%$, $\mathrm{P}=0.55$ ), and the net clinical outcome end point (11.5\% and $11.8 \%, \mathrm{P}=0.75)$. Baseline renal insufficiency was associated with an increased rate of hemorrhagic complications with all antithrombotic agents. However, the relative increase in the rate of major bleeding associated with a baseline calculated creatinine clearance of less than $60 \mathrm{ml}$ per minute, as compared with $60 \mathrm{ml}$ per minute or more, was similar among patients receiving enoxaparin, those receiving unfractionated heparin, and those receiving bivalirudin monotherapy $(9.5 \%$ and $4.4 \%, 10.1 \%$ and $4.9 \%$, and $6.2 \%$ and $2.4 \%$, respectively).

\section{DISCUSSION}

In this large-scale, prospective, randomized trial involving patients with moderate- or high-risk acute coronary syndromes who were undergoing early invasive management, the use of bivalirudin plus a glycoprotein IIb/IIIa inhibitor was associated with rates of ischemic and hemorrhagic complications that were noninferior to those associated with the use of heparin (either unfractionated heparin or enoxaparin) plus a glycoprotein IIb/IIIa inhibitor. In contrast, bivalirudin monotherapy, with provisional use of glycoprotein IIb/IIIa inhibitors in less than $10 \%$ of patients, was associated with rates of ischemic events that were noninferior to those associated with heparin plus glycoprotein IIb/IIIa inhibition but was associated with a significantly reduced incidence of major bleeding.

Formal subgroup analysis revealed no significant interactions between the primary study end points and numerous important demographic and treatment variables, with the possible exception of the administration of a thienopyridine before angiography or PCI. Although the time from administration of the study drug to angiography was relatively short (reflecting the growing rec- 
ognition that clinical outcomes are optimized with rapid catheterization in acute coronary syndromes), ${ }^{21}$ bivalirudin monotherapy was also associated with a significantly lower risk of bleeding and similar rates of ischemia in the subgroup of patients for whom the interval from randomization to angiography or intervention was more than 24 hours.

In approximately $64 \%$ of patients, a thienopyridine (clopidogrel in most instances) was already in use or was administered before angiography or PCI. In such patients, the point estimate for composite ischemic events was similar with bivalirudin monotherapy and with heparin plus glycoprotein IIb/IIIa inhibitors. In contrast, the point estimate for adverse ischemic events was slightly greater with bivalirudin monotherapy than with heparin plus glycoprotein IIb/IIIa inhibitors in patients who were not pretreated with a thienopyridine. Information about the exact timing of pretreatment with clopidogrel was not available for all patients, and platelet responsiveness testing was not performed, precluding an in-depth examination of the relationship between inhibition of the $\mathrm{P}_{12}$ platelet receptor and the efficacy of bivalirudin. Moreover, given the borderline statistical significance of the interaction $(\mathrm{P}=0.054)$ and the risk of a spurious finding from examination of multiple subgroups, caution against overinterpretation is warranted. ${ }^{22}$ Nonetheless, the administration of a thienopyridine before angiography may be desirable to optimize outcomes with a regimen of bivalirudin monotherapy, an approach that is consistent with experimental observations..$^{23,24}$

Several limitations of the present study deserve comment. First, the logistic complexities of the trial necessitated an open-label design, which introduced the potential for bias. However, the frequency of the provisional use of glycoprotein IIb/ IIIa inhibitors for procedural complications related to PCI among patients in the group receiving bivalirudin monotherapy was nearly identical to that in the double-blind REPLACE- 2 trial, ${ }^{9}$ and all endpoint events were adjudicated by an independent committee that was unaware of the treatment assignments.

Second, $59 \%$ of the study cohort presented with myocardial infarction without ST-segment elevation, a percentage lower than that in the Superior Yield of the New Strategy of Enoxaparin, Revascularization and Glycoprotein IIb/IIIa Inhibitors (SYNERGY) trial (which specifically recruited only high-risk patients), ${ }^{13}$ though similar to the percentage in other recent large-scale trials of acute coronary syndromes. ${ }^{25,26}$ Nevertheless, adverse composite ischemic events occurred with nearly identical frequency in patients in the control and bivalirudin-monotherapy groups, even among the highest-risk patients enrolled (i.e., 2449 patients with a TIMI risk score of 5 to 7). Bivalirudin monotherapy was also particularly effective in the subgroup of patients with baseline TIMI risk scores of 0 to 2. However, enrollment criteria were such that $80.1 \%$ of this subgroup met the classic highrisk criteria for either positive biomarkers or STsegment deviation at baseline. The results of the present study do not apply, however, to patients with acute coronary syndromes that are managed either solely with a noninvasive strategy, without diagnostic angiography and intended revascularization, or for a prolonged period ( $>72$ hours) before catheterization. Further study is also required to determine the optimal pharmacologic regimen for patients with severe renal insufficiency (creatinine clearance, $<30 \mathrm{ml}$ per minute), who were excluded from enrollment.

Third, as in other recent acute coronary syndrome trials, ${ }^{13}$ a significant proportion of patients were pretreated with either unfractionated or lowmolecular-weight heparin before randomization. Protocol procedures limited the rate of intragroup crossovers from treatment before to treatment after randomization to less than $6 \%$ in the control group, whereas more than $60 \%$ of patients assigned to bivalirudin were exposed to heparin before randomization. Nonetheless, the effects of bivalirudin monotherapy as compared with heparin plus a glycoprotein IIb/IIIa inhibitor were consistent, regardless of whether an antithrombotic crossover occurred, as demonstrated in subgroup analyses.

Fourth, the $25 \%$ noninferiority margin that we used may be considered wide. Because the observed rate of ischemic events in the control group was 7.3 percent, an estimated ischemic-event rate as high as $9.1 \%$ in the test groups would have been considered noninferior, even though it might be regarded as clinically important. However, given the observed event rates and confidence intervals, there was a $95.0 \%$ likelihood that the incidence of composite ischemia in the bivalirudin-monotherapy group is less than $20 \%$ higher than the incidence in the control group.

In summary, we found that in patients with 
unstable angina or myocardial infarction without ST-segment elevation who were undergoing early invasive management, the rates of ischemic events and bleeding were similar with the use of either bivalirudin or heparin when combined with the planned use of a glycoprotein IIb/IIIa inhibitor. When bivalirudin was used without a glycoprotein IIb/IIIa inhibitor, the frequency of ischemic events was similar to that with heparin plus a glycoprotein IIb/IIIa inhibitor, but the frequency of major bleeding was significantly reduced.

Supported by the Medicines Company and Nycomed.

Dr. Stone reports receiving consulting fees from the Medicines Company, Boston Scientific, Guidant, Abbott, Volcano, St. Jude, and BMS Imaging and lecture fees from the Medicines Company, Boston Scientific, Nycomed, Guidant, Medtronic, and Abbott; Dr. Cox, consulting fees and lecture fees from the Medicines Company, Boston Scientific, Guidant, St. Jude, and Cordis Dr. Bertrand, consulting fees and lecture fees from Servier and Sanofi-Aventis; Dr. Lincoff, consulting fees from the Medicines Company, Mitsubishi Pharmaceuticals, and PrognostiX, lecture fees from the Medicines Company, and grant support from the Medicines Company, Pfizer, and Sanofi-Synthelabo; Dr. Moses, consulting fees from Cordis Johnson \& Johnson and lecture fees from AstraZeneca; Dr. White, consulting fees and lecture fees from the Medicines Company and Sanofi-Aventis and grant support from the Medicines Company, Sanofi-Aventis, Procter \& Gamble, Schering-Plough, Eli Lilly, Alexion, Merck, Neuren Pharmaceuticals, GlaxoSmithKline, Pfizer, Roche, Fournier Laboratories, and Johnson \& Johnson; Dr. Pocock, consulting fees from the Medicines Company; and Dr. Ware, consulting fees from the Medicines Company, Biogen, InfraReDx, and Schering Plough. Dr. Feit reports having equity interests in the Medicines Company, Johnson \& Johnson, and Millennium Pharmaceuticals, and receiving consulting fees from the Medicines Company. Dr. Aylward reports receiving consulting fees and lecture fees from Sanofi-Aventis, Bristol-Myers Squibb and CSL Limited and grant support from the Medicines Company, Sanofi-Aventis, Procter \& Gamble, Alexion, Schering-Plough, and Eli Lilly; Dr. Darius, advisory board fees from Nycomed, Sanofi-Aventis, Boehringer
Ingelheim, and Essex Pharma and lecture fees from Sanofi-Aventis, Bristol-Myers Squibb, Nycomed, and AstraZeneca; and Dr. Desmet, consulting fees from Nycomed and grant support from Medtronic, Guidant, and Eli Lilly. Dr. Ebrahimi reports having received consulting fees from the Medicines Company, SanofiAventis, Bristol-Myers Squibb, and Guerbet, having equity interests in the Medicines Company and Sanofi-Aventis, and receiving lecture fees from the Medicines Company, Sanofi-Aventis, and Bristol-Myers Squibb and grant support from Abbott. Dr. Hamon reports receiving advisory board fees from Nycomed, consulting fees from Terumo, Cordis, Guidant, and Biotronik, and lecture fees from Nycomed, Merck, Sanofi-Synthelabo, AstraZeneca, Boston Scientific, Guidant, Terumo, Cordis, Medtronic, and Biotronik; Dr. Rasmussen, advisory board fees and lecture fees from Nycomed; Dr. Rupprecht, consulting fees and lecture fees from Nycomed, GlaxoSmithKline, Eli Lilly, and SanofiAventis; Dr. Hoekstra, consulting fees from the Medicines Company, Sanofi-Aventis, and Schering-Plough, lecture fees from the Medicines Company, Sanofi-Aventis, Bristol-Myers Squibb, and Schering-Plough, and grant support from the Medicines Company and Schering-Plough; and Dr. Mehran, lecture fees from the Medicines Company, Cordis, and Boston Scientific. Dr. Ohman reports receiving consulting fees from the Medicines Company, SanofiAventis, Liposcience, Inovise Medical, Response Biomedical, and Savacor, having equity interest in Medtronic and Savacor, having received lecture fees from Schering-Plough, Bristol-Myers Squibb, and Datascope, and receiving grant support from ScheringPlough, Bristol-Myers Squibb, and Berlex. Drs. Stone, Moses, and Mehran report that grant support from the Medicines Company has been received by the Cardiovascular Research Foundation, a public charity of which they are directors but from which they receive no compensation. Dr. Lincoff reports that grant support from the following sources has been received by the Cleveland Clinic Cardiovascular Coordinating Center, an academic research organization within the Department of Cardiovascular Medicine at the Cleveland Clinic, of which Dr. Lincoff is the director: Alexion, American Bioscience, AstraZeneca, Atherogenics, Aventis, Biosite, Centocor, Converge Medical, Cordis, Eli Lilly, Glaxo Wellcome, GlaxoSmithKline, Guilford, the Medicines Company, Medtronic, Novartis, Orphan Therapeutics, Pfizer, Pharmacia \& Upjohn, Philips, Sankyo, Sanofi, Sanofi-Synthelabo, Scios, Takeda America, and Vasogenix. No other potential conflict of interest relevant to this article was reported.

\section{REFERENCES}

1. Graves EJ, Kozak LJ. Detailed diagnosis and procedures, National Hospital Dis charge Survey, 1996. No. 138. Hyattsville, MD: National Center for Health Statistics, 1998. (DHHS publication no. 98-1799.) 2. Mehta SR, Cannon CP, Fox KA, et al Routine vs selective invasive strategies in patients with acute coronary syndromes: a collaborative meta-analysis of random ized trials. JAMA 2005;293:2908-17.

3. Braunwald E, Antman EM, Beasley JW et al. Management of patients with un stable angina and non-ST segment elevation myocardial infarction: a report of the American College of Cardiology/American Heart Association Task Force on Practice Guidelines (Accessed October 30, 2006, at http://www.acc.org/qualityandscience/ clinical/guidelines/unstable/unstable_ pkt.pdf.)

4. Braunwald E, Antman EM, Beasley JW, et al. ACC/AHA guideline update for the management of patients with unsta- ble angina and non-ST-segment elevation myocardial infarction - 2002: summary article: a report of the American College of Cardiology/American Heart Association Task Force on Practice Guidelines (Committee on the Management of Patients With Unstable Angina). Circulation 2002;106 1893-900.

5. Bertrand ME, Simoons ML, Fox KA et al. Management of acute coronary syndromes in patients presenting without persistent ST-segment elevation. Eur Heart J 2002;23:1809-40. [Errata, Eur Heart J 2003; 24:485, 1174-5.]

6. Moscucci M, Fox KA, Cannon CP, et al. Predictors of major bleeding in acute coronary syndromes: the Global Registry of Acute Coronary Events (GRACE). Eu Heart J 2003;24:1815-23.

7. Segev A, Strauss BH, Tan M, et al. Predictors and 1-year outcome of major bleeding in patients with non-ST-elevation acute coronary syndromes: insights from the $\mathrm{Ca}-$ nadian Acute Coronary Syndrome Registries. Am Heart J 2005;150:690-4

8. Rao SV, Jollis JG, Harrington RA, et al. Relationship of blood transfusion and clinical outcomes in patients with acute coronary syndromes. JAMA 2004;292: 1555-62.

9. Lincoff AM, Bittl JA, Harrington RA, et al. Bivalirudin and provisional glycoprotein IIb/IIIa blockade compared with heparin and planned glycoprotein IIb/III blockade during percutaneous coronary intervention: REPLACE-2 randomized trial. JAMA 2003;289:853-63. [Erratum, JAMA 2003;289:1638.]

10. Lincoff AM, Kleiman NS, Kereiakes DJ, et al. Long-term efficacy of bivalirudin and provisional glycoprotein IIb/IIIa blockade vs heparin and planned glycoprotein IIb/IIIa blockade during percutaneous coronary revascularization: REPLACE-2 randomized trial. JAMA 2004;292:696-703. [Erratum, JAMA 2006;296:46.] 
11. Stone GW, Bertrand M, Colombo A, et al. Acute Catheterization and Urgent Intervention Triage strategY (ACUITY) trial study design and rationale. Am Heart J 2004;148:764-75.

12. Antman EM, Cohen M, Bernink PJ, et al. The TIMI risk score for unstable angina/non-ST elevation MI: a method for prognostication and therapeutic decision making. JAMA 2000;284:835-42.

13. Ferguson JJ, Califf RM, Antman EM, et al. Enoxaparin vs unfractionated heparin in high-risk patients with non-STsegment elevation acute coronary syndromes managed with an intended early invasive strategy: primary results of the SYNERGY randomized trial. JAMA 2004 292:45-54.

14. Fuchs J, Cannon C. Hirulog in the treatment of unstable angina: results of the Thrombin Inhibition in Myocardial Ischemia (TIMI) 7 trial. Circulation 1995;92 727-33.

15. Antman EM, McCabe CH, Braunwald E. Bivalirudin as a replacement for unfractionated heparin in unstable angina/nonST-elevation myocardial infarction: observations from the TIMI 8 trial. Am Heart ) 2002;143:229-34.

16. The PURSUIT Trial Investigators. In- hibition of platelet glycoprotein IIb/IIIa with eptifibatide in patients with acute coronary syndromes. N Engl J Med 1998 339:436-43.

17. The PRISM-PLUS Study Investigators. Inhibition of the platelet glycoprotein IIb IIIa receptor with tirofiban in unstable angina and non-Q-wave myocardial infarction. N Engl J Med 1998;338:1488-97. [Erratum, N Engl J Med 1998;339:415.]

18. The EPISTENT Investigators. Randomised placebo-controlled and balloonangioplasty-controlled trial to assess safety of coronary stenting with use of platelet glycoprotein-IIb/IIIa blockade. Lancet 1998 352:87-92.

19. ESPRIT Investigators. Novel dosing regimen of eptifibatide in planned coronary stent implantation (ESPRIT): a randomised, placebo-controlled trial. Lancet 2000;356:2037-44. [Erratum, Lancet 2001; 357:1370.]

20. Benjamini Y, Hochberg Y. Controlling the false discovery rate: a practical and powerful approach to multiple testing. J R Stat Soc B 1995;57:289-300.

21. Neumann FJ, Kastrati A, PogatsaMurray G, et al. Evaluation of prolonged antithrombotic pretreatment ("cooling off" strategy) before intervention in pa- tients with unstable coronary syndromes: a randomized controlled trial. JAMA 2003; 290:1593-9.

22. Hernandez AV, Boersma E, Murray GD, Habbema JD, Steyerberg EW. Subgroup analyses in therapeutic cardiovascular clinical trials: are most of them misleading? Am Heart J 2006;151:257-64. 23. André P, LaRocca T, Delaney SM, et al. Anticoagulants (thrombin inhibitors) and aspirin synergize with $\mathrm{P}_{2} \mathrm{Y}_{12}$ receptor antagonism in thrombosis. Circulation 2003;108:2697-703.

24. Nylander S, Mattsson C, Ramstrom S, Lindahl TL. Synergistic action between inhibition of $\mathrm{P}_{2} \mathrm{Y}_{12} / \mathrm{P}^{2} \mathrm{Y}_{1}$ and $\mathrm{P}_{2} \mathrm{Y}_{12} /$ thrombin in ADP- and thrombin-induced human platelet activation. Br J Pharmacol 2004; 142:1325-31

25. Kastrati A, Mehilli J, Neumann FJ, et al. Abciximab in patients with acute coronary syndromes undergoing percutaneous coronary intervention after clopidogrel pretreatment: the ISAR-REACT 2 randomized trial. JAMA 2006;295:1531-8.

26. Yusuf S, Mehta SR, Chrolavicius S, et al. Comparison of fondaparinux and enoxaparin in acute coronary syndromes. $\mathrm{N}$ Engl Med 2006;354:1464-76.

Copyright $(\odot 2006$ Massachusetts Medical Society.

VIEW CURRENT JOB POSTINGS AT THE NEJM CAREERCENTER Visit our online CareerCenter for physicians at www.nejmjobs.org to see the expanded features and services available. Physicians can conduct a quick search of the public database by specialty and view hundreds of current openings that are updated daily online at the CareerCenter. 